\title{
Celecoxib, a COX-2 Selective Inhibitor, Induces Cell Cycle Arrest at the G2/M Phase in HeLa Cervical Cancer Cells
}

\author{
Agustina Setiawati
}

\begin{abstract}
Celecoxib, a selective inhibitor of $\mathrm{COX}-2$, showed cytotoxic effects in many cancer cell lines including cervical cancer cells. This study investigated the effect of celecoxib on cell cycle arrest in HeLa cervical cancer cells through p53 expression. In vitro anticancer activity was determined with the 3-[4,5-dimethylthiazol-2-yl]-2,5 diphenyl tetrazolium bromide (MTT) method. A double staining method was applied to investigate the mechanism of cell death, cell cycling was analyzed by flow cytometryand immunocytochemistry was employed to stain p53 expression in cells. Celecoxib showed strong cytotoxic effects and induced apoptosis with an $\mathrm{IC}_{50}$ value of 40 $\mu \mathrm{M}$. It induced cell cycle arrest at G2/M phase by increasing level of p53 expression on HeLa cells.
\end{abstract}

Keywords: Celecoxib - HeLa cells - apoptosis - cell cycle - p53

Asian Pac J Cancer Prev, 17 (4), 1655-1659

\section{Introduction}

Cervical cancer is the third most common diagnosed cancer and leading cause of the death among female worldwide (Vici et al., 2014; Torre et al., 2015). (Kimman et al., 2012) reported that it was the second highest incidence of cancer in ASEAN female. in Indonesia, it was ranked as the third most commonly caused of female death of cancer. The burden of this disease is majority in low and middle income country (Sahasrabuddhe et al., 2013). The pattern of cervical cancer shifted from more developed to less developed country (Torre et al., 2015). Since the incidence is rapidly rising, many drugs were developed to prevent and treat cervical cancer. Many studies work on new cervical cancer drugs by targeting specific biomarker without effecting normal cells.

Drug discovery and development is a very complex process and costly. It needs approximately US $\$ 802$ million for 10 to 20 years to bring a drug from laboratory to market (Dickson and Gagnon, 2009). Drug repurposing is one of alternative approach to increase the effectivity of drug discovery (Gupta et al., 2013). Celecoxib(4-[5(4-methylphenyl)-3- (trifluoromethyl)-1H-pyrazol-1-yl] benzenesulfon-amide), a selective cyclooxygenase-2 (COX-2) inhibitor, is a potentially developed as anticancer in cervical cancer. It was first launched by US Food and Drug Administration in 2009 to treat osteoarthritis (Audo et al., 2007; Zweers et al., 2011). COX-2 expression is linked to cancer progression including cervical cancer. When Human Papiloma Virus (HPV) infected cervical cells, it inserted E6 and E7 oncogene that induced COX-2 expression in cells (Kim et al., 2013).

In vitro studies reported celecoxib revealed cytotoxic activity on cervical, liver, colon, breast, gastric and prostate cancer cells (Hsu et al., 2000; Kim et al., 2004, 2007; Ang et al., 2012; Wang et al., 2009, 2013; Chu et al., 2013). In cervical cancer cells, it induced cell cycle arrest at $\mathrm{G} 1$ and $\mathrm{G} 2 / \mathrm{M}$ phase depended on its concentration (Kim and Pyo, 2013). However, the molecular mechanism of celecoxib through p53 was still unclear. Protein p53 is a key inducer of apoptosis and cell cycle arrest process (Nair et al., 2003; Li et al., 2012) by degrading E6 and E7 oncogene (Nair et al., 2003). p53, a tumor suppressor gene, was frequently mutated in several cancer cell lines but the mutation of p53 was low frequent in cervical cancer (Pinheiro and Villa, 2001).p53 is potential biomarker that could be investigated in HeLa cells. This work focused on molecular mechanism of celecoxib on HeLa cervical cancer cell line by inducing apoptosis and cell cycle arrest through p53 expression.

\section{Materials and Methods}

Cytotoxic, Apoptosis, Flowcytometry and Immunocytochemistry

The sample of this study was prepared from celecoxib (Sigma) with $99.995 \%$ purity while cisplatin as positive control was prepared from Cisplatin Kalbe. This subject of this study was HeLa cells, a cell culture collection of Parasitology Department, Faculty of Medicine, Universitas Gadjah Mada. The cells were maintained in Dubelcco Modified Eagle Media (Gibco) containing Fetal 


\section{Agustina Setiawati}

Bovine Serum (FBS) 10\% (v/v) (Gibco) and penicilinstreptomycin 1\% (v/v) (Gibco). Cytotoxic assay was measured by 3-[4,5-dimethylthiazol-2-yl]-2,5 diphenyl tetrazolium bromide (MTT) (Sigma) method while the apoptosis assay was examined by ethidium bromide and acridine orange (Sigma) staining. Propidium iodide reagent contained $0.1 \%$ triton X (E.Merck, Germany), $0.2 \%$ RNAse and $5 \%$ propidium iodide (Sigma) in Phosphate Buffer Saline (PBS). Immunocytochemistry used p53 primary antibody purchased form Novus Bio NB 200-103, while the universal secondary antibody was derived from Starr Trek Universal HRP Detection System No.901-STUHRP700-090314. All culture plates used in this study were Iwaki ${ }^{\circledR}$ and all tips and micro tubes were supplied by Axigen ${ }^{\circledR}$.

\section{MTT cytotoxic assay}

Cytotoxic assay was designed based on previous study on HeLa cells (Yuliani et al., 2015). The cells were cultured in culture tissue flask until 70-80\% confluent, and then $5 \times 10^{3}$ cells were seeded into 96-well plate. The plate was incubated at $37^{\circ} \mathrm{C}$ and $5 \% \mathrm{CO}_{2}$ for 24 hours. The medium was removed and the cells were rinsed twice by using PBS. The stock solution of celecoxib was prepared by dissolving them into DMSO and diluted them in medium into various concentrations. Each concentration (100 $\mu \mathrm{L} /$ well) was added into 96-well plate and measured in triplicates. Later, the plate was incubated at $37^{\circ} \mathrm{C}$ and under $5 \% \mathrm{CO}_{2}$ for 24 hours. The medium was removed and $10 \%$ MTT containing medium was added into each well. The plate was further incubated in the same as previous condition for 4 hours. At the end of incubation time, 100 $\mu \mathrm{L}$ SDS was added to each well to dissolve formazan crystals. The plate was incubated in dark room for 12-24 hours and formazan crystals were measured by using ELISA reader at a wavelength of $595 \mathrm{~nm}$.

\section{Apoptosis induction assay}

HeLa cells were seeded into coverslips in 24-well plate (5x104/well). The cells were adapted at $37 \mathrm{oC}$ and $5 \% \mathrm{CO} 2$ for 24 hours. The medium was removed and twice rinsed by using PBS. The celecoxib and cisplatin at $40 \mu \mathrm{M}$ concentration were added into the plate and incubated in the same condition as previously described. The medium was removed from the cells and rinsed by using PBS. The coverslips transferred to object glasses, then acridine orange-ethidium bromide (AE) was dropped into the coverslips. The cells were immediately observed under fluorescence microscope (Yuliani et al., 2015).

\section{Cell cycle analysis}

HeLa cells were seeded in a 6 well plate at a density of $1 \times 10^{6}$ cells each well. After 24 hours incubation, celecoxib and cisplatin at concentration $40 \mu \mathrm{M}$ were added to the respective flask and incubated for 12 and 24 hours. The cells were removed and harvested from flask using tripsin. After incubation, the cells were centrifuged at $2000 \mathrm{rpm}$ for 3 minutes. The cells were washed using cold phosphate buffer saline (PBS) three times. The pellets were resuspended in $500 \mu \mathrm{L}$ propidium iodine $(10 \mu \mathrm{g} / \mathrm{mL}$ ) containing $300 \mu \mathrm{g} / \mathrm{mL}$ RNase (Sigma, MO,
USA). The cells were incubated at $37^{\circ} \mathrm{C}$ for 10 minutes in waterbath. Cell suspension was homogenized and transferred in flowcyto tube. Then the cells were analyzed by flowcytometer.

\section{Immunocytochemistry assay}

HeLa cells were cultured in 6-well plate and incubated under $5 \% \mathrm{CO}_{2}$ and $37^{\circ} \mathrm{C}$ for 24 hours. Celecoxib and cisplatin at $40 \mu \mathrm{M}$ concentration were added to the cells and incubated for further 24 hours. At the end of incubation time, cells were collected and washed by PBS. The cells were suspended in medium, placed and fixed in object glass for 5 minutes. Hydrogen peroxidase was dropped into the object glass and incubated at room temperature for 10-15 minutes. The cells were washed twice with PBS and monoclonal antibody of p53 was added into the cells and incubated at least for an hour at room temperature. The cells were washed three times with PBS and added with secondary antibody, incubated at room temperature for ten minutes, and washed four times with PBS. The solution of 3, 3'-diaminobenzidine (DAB), as chromogen, was added to the cells and incubated for 3-8 minutes. Finally, the cells were washed with distilled water and added with hematoxylin solution followed by 3-4 minutes incubation. The expression of p53 was observed under inverted microscope (Yuliani et al., 2015).

\section{Data analysis}

To calculate $\mathrm{IC}_{50}$ of celecoxib and cisplatin, the viability data was plotted in linear regression using Microsoft Excel 2013. Apoptotic, necrotic and living cells was qualitatively counted in three different areas of the object glass. This analysis was performed in triplicate of each treatment. Cell cycle distribution was calculated from 10,000 cells with ModFit LT 3.0 TM software using FACScaliber. The number of p53 expressing cells was qualitatively analyzed.

\section{Results}

This study determined anticancer activity of celecoxib on HeLa cervical cancer cells by arresting cell cycle through inducing p53 expression. Cytotoxic effect was assessed with MTT assays that measured absorbance of

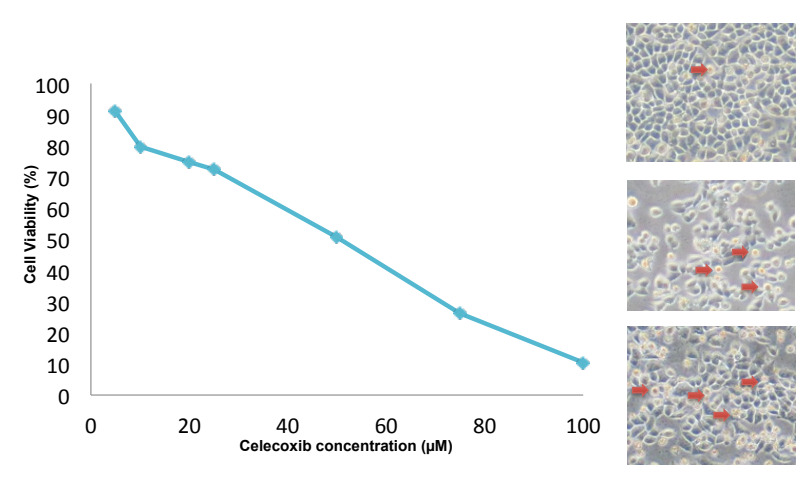

Figure 1. Celecoxib and Cisplatin Effect on HeLa Cells Viability and Morphology. (a) Untreated Cells, (b) $40 \mu \mathrm{M}$ Celecoxib, (c) $40 \mu \mathrm{M}$ Cisplatin. Red arrows showed the death cells in population 


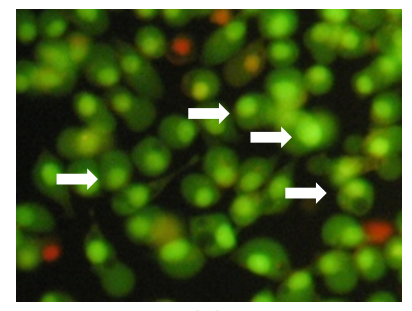

(a)

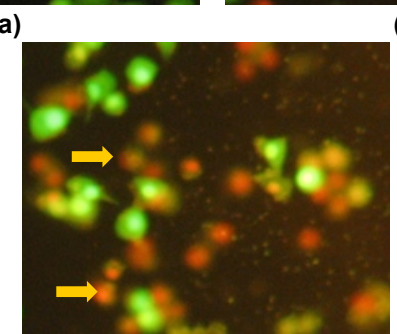

(c)

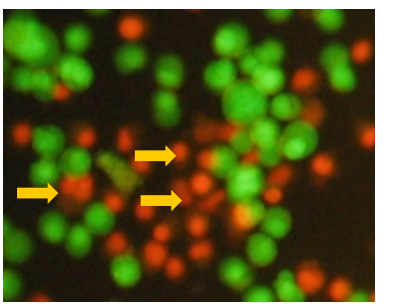

(b)

Figure 2. Observation of Cells on Double Staining Method Under Flourecence Microscope Using 400X Magnification.(A)Untreated cells, (B) Celecoxib $40 \mu \mathrm{M}$ (C) Cisplatin $40 \mu \mathrm{M}$. White arrows showed living cells and yellow arrows showed apoptotic cells

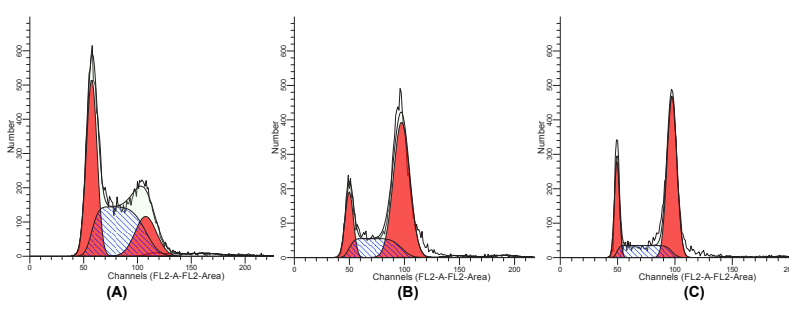

Figure 3. Analysis of Cell Cycle Progression. HeLa cells were (A) Untreated, (B) $40 \mu \mathrm{M}$ celecoxib and (C) $40 \mu \mathrm{M}$ cisplatin. The cells were harvested after 24 hours then they were analyzed for DNA content. The distribution and percentage of cells in pre-phase, $\mathrm{G} 1, \mathrm{~S}$ and $\mathrm{G} 2 / \mathrm{M}$ phase of the cell cycle were indicated

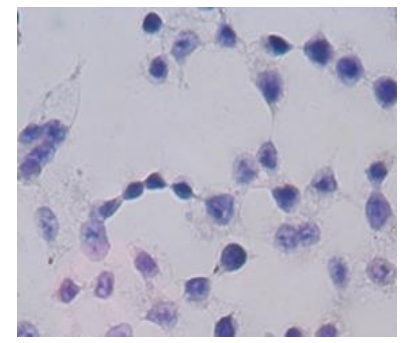

(A)

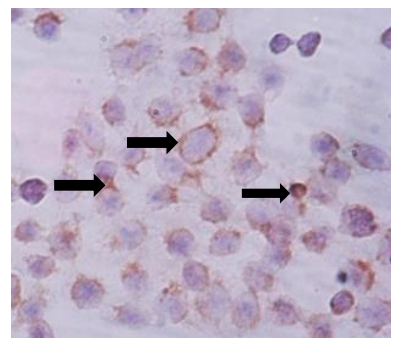

(B)

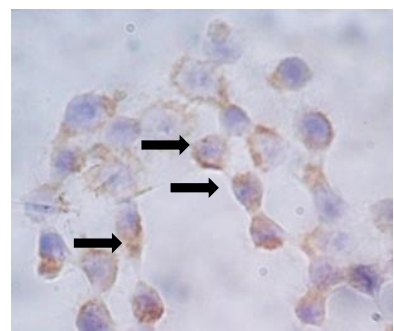

(C)

Figure 4. The Observation of p53 Expression on HeLa cells by Using Imunocytochemistry Method Under Light Microscope in 400x Magnification. (A)Untreated cells (B) Cells treated with $40 \mu \mathrm{M}$ celecoxib. (C) Cells treated with $40 \mu \mathrm{M}$ cisplatin. Brown colour (black arrows) in cells refer to $\mathrm{p} 53$ expression formazan complex at $595 \mathrm{~nm}$ that equaled to the number of living cells. As presented in Figure 1, celecoxib showed dose dependent cytotoxic activity $\left(\mathrm{R}_{2}=0.9924\right)$ on HeLa cells with $\mathrm{IC}_{50} 43 \mu \mathrm{M}$, respectively. Cisplatin was used as positive control since it was widely used as therapy in cancer patient (Dasari and Tchounwou, 2014; Vici et al., 2014).

Based on our previous work, cisplatin performed cytotoxic activity and apoptosis induction on HeLa cells with $\mathrm{IC}_{50} 40 \mu \mathrm{M}$ (Yuliani et al., 2015). Celecoxib and cisplatin changed HeLa cells morphology and induced cell death at concentration $40 \mu \mathrm{M}$. Double staining method investigated the mechanism of cells death (Figure 2). Celecoxib and cisplatin induced apoptosis in HeLa cells. This method clearly identified apoptosis stage insignificant different from flowcytometry method (Liu et al., 2015).

Cell cycle analysis counted that HeLa cells were accumulated on G2/M phase in celecoxib (61.70\%) and cisplatin treatment $(56.65 \%)$ compare to untreated cells (17.41\%) (Figure 3). Molecular mechanism of cell cycle arrest was determined by immunocytochemistry method. Since p53 is a major regulator of apoptosis pathway and cell cycle arrest, further we investigated p53 expression. HeLa cells that express p53 were stained as intense brown color in nuclei while none were stained as blue color. Qualitative analysis of Figure 4 indicated that both of celecoxib and cisplatin increased p53 expression. This data suggested that cytotoxic activity of celecoxib induced cell cycle arrest through inducing p53 expression in HeLa cells.

\section{Discussion}

This pre-clinical study investigated celecoxib repurposing to be anticancer drug on cervical cancer. Previous research revealed celecoxib had cytotoxic effect and induced apoptosis in HeLa cervical cancer cells (Kim et al., 2007, 2004). Non Steroid Inflammation Drugs (NSAIDs), including selective COX-2 inhibitor, have been associated with reduced incidence and mortality in many cancer cells (Gurpinar et al., 2013; Setiawati et al., 2016). Since it inhibited COX-2 expression, celecoxib reduced prostaglandin E2 and thromboxane A2 that play important role in cell proliferation, invasion and survival (Allaj et al., 2013). Moreover, molecular mechanism was not always associated with COX-2 expression (Kang et al., 2009; Kim et al., 2004). The study of Ang and colleagues (2012) showed by reducing COX-2, celecoxib sensitized radiotherapy in HeLa cells (Ang et al., 2012). However, COX-2 expression increased survival on cervical cancer patients (Doll et al., 2013). Therefore, other proteins might interference anticancer activity of celecoxib.

In this study, cisplatin was used as positive control since it was clinically used in cervical cancer therapy both single and combination (Vici et al., 2014; Grigsby et al., 2013). It revealed drug resistance (Galluzzi et al., 2014) and severe side effect such as kidney toxicity, allergic reaction, immunity problem, gastrointestinal disorder, hemorrhage and hearing loss (Dasari and Bernard Tchounwou, 2014). Celecoxib performed strong cytotoxic activity and induced apoptosis on HeLa cells (Figure 1 
and 2). Based on $\mathrm{IC}_{50}$ value, celecoxib $\left(\mathrm{IC}_{50}=43 \mu \mathrm{M}\right)$ had strong cytotoxic activity equal to cisplatin in HeLa cells.

Cell cycle regulation is an essential target in HPVassociated carcinogenesis (Fernandes and Syrjanen, 2003). Flow cytometry data showed that HeLa cells were primarily arrested in the $\mathrm{G} 2 / \mathrm{M}$ phase due to celecoxib and cisplatin treatment (Figure 3). Since G1 and G2/M checkpoint in cell cycle are interfered by HPV in cervical cancer (Fernandes and Syrjanen, 2003), anticancer drugs possibly address on both of cell cycle. Other effects of celecoxib and cisplatin on cell cycle progression were reported it induced cell cycle arrest in different phase. At different concentration, cisplatin induced G1 arrest in HeLa cells (Larasati et al., 2014). Celecoxib induced different cell cycle arrest at G1 phase in bladder, glial and colon cancer (Gee et al., 2009; Kang et al., 2009; Kim and Pyo, 2013). In cervical cancer, celecoxib induced cell cycle arrest in G1 and G2/M phase depended on its concentration (Kang et al., 2009).

To observe molecular target, this study targeted p53 as a key protein that responsible to apoptosis and cell cycle arrest. Vast efforts based on p53 activation had been successfully treat cancer (Lane et al., 2010; Chen et al., 2010), especially cervical cancer (Lee et al., 2006). Both of celecoxib and cisplatin induced p53 expression in HeLa cells to arrest cell cycle at G2/M phase (Figure 4). This finding opened an interesting question whether p53 expression involved in apoptosis and cell cycle arrest in HeLa cells. Based on our p53 immunocytochemistry data, both of celecoxib and cisplatin executed apoptosis and cell cycle arrest by involving p53. Stabilization of p53 possibly pushed cell cycle arrest at G2/M phase and apoptosis in HeLa cells (Larasati et al., 2014). When p53 is activated, it stimulates cell cycle arrest and induces apoptosis (Pflaum et al., 2014). Active form of p53 activated several genes which were involved in G1, S and G2/M arrest. Therefore, it might induce multiple cell cycle arrest (Garofalo and Surmacz, 2006). Another possible molecular mechanism was reported by Kim and colleagues (2007) that celecoxib induced apoptosis in cervical cancer cells through GADD135, a transcription factor. Target proteins which are activated by p53, involving apoptosis and cell cycle arrest HeLa cells, are suggested to be observed in further study to settle detailed molecular pathway of celecoxib.

In conclusion, celecoxib induced cell cycle arrest at G2/M phase through inducing p53 expression on HeLa cervical cancer cells. It is interesting to investigate p53dependent molecular pathway in further study.

\section{Acknowledgements}

This work was funded by Institute for Research and Public Affair, Universitas Sanata Dharma (Internal Research Grant No.025/Penelitian Internal USD/ STP/2015).

\section{References}

Allaj V, Guo C, Nie D (2013). Non-steroid anti-inflammatory drugs, prostaglandins, and cancer. Cell Biosci, $\mathbf{3}, 8$.

Ang AHW, Ian XYT, Yu JJ, et al (2012). Celecoxib Radiosensitizes the Human Cervical Cancer HeLa Cell Line via a Mechanism Dependent on Reduced Cyclo-oxygenase-2 and Vascular Endothelial Growth Factor C Expression. J Internl Med Res, 40, 56-66.

Audo R, Deschamps V, Hahne M, Combe B, et al (2007). Apoptosis is not the major death mechanism induced by celecoxib on rheumatoid arthritis synovial fibroblasts. Arthritis Res Ther, 9, 128.

Chen F, Wang W, El-Deiry WS (2010). Current strategies to target p53 in Cancer. Biochemical Pharmacol, 80, 727- 30.

Chu T, Chan H, Kuo H, Liu L, et al (2013). Celecoxib suppresses hepatoma stemness and progression by up-regulating PTEN. Oncotarget, 5, 1475- 90.

Dasari S, Tchounwou BP (2014). Cisplatin in Cancer therapy: Molecular mechanisms of action. Eur J Pharmacol, 740, 364-78.

Doll CM, Winter K, Gaffney DK et al (2013). COX-2 Expression and survival in patients with locally advanced cervical cancer treated with chemoradiotherapy and celecoxib: A quantitative immunohistochemical analysis of RTOG C0128. Int J Gynecol Cancer, 23, 176-83.

Fernandes SM, Syrjanen KJ (2003). Regulation of cell cycles is of key importance in human papillomavirus (HPV)-asociated cervical carcinogenesis. Sao Paulo Med J, 121, 128-32.

Galluzzi L, Vitale I, Michels J, Brenner C, et al (2014). Systems biology of cisplatin resistance: past, present and future. Cell Death Dis, 5, 1257.

Garofalo C, Surmacz E (2006). Leptin and cancer. J Cell Physiol, 207, 12-22.

Grigsby PW, Zighelboim I, Powell MA, et al (2013). In vitro chemoresponse to cisplatin and outcomes in cervical cancer. Gynecol Oncol, 130, 188-91.

Gupta SC, Sung B, Prasad S, Webb LJ, et al (2013). Cancer drug discovery by repurposing: Teaching new tricks to old dogs. Trends Pharmacol Sci, 34, 508-17.

Gurpinar E, Grizzle WE, Piazza G (2013). COX-Independent Mechanisms of Cancer Chemoprevention by AntiInflammatory Drugs. Front Oncol, 3, 1- 18.

Hsu AL, Ching TT, Wang DS, et al (2000). The cyclooxygenase-2 inhibitor celecoxib induces apoptosis by blocking Akt activation in human prostate cancer cells independently of Bcl-2. J Biol Chem, 275, 11397-1403.

Kang KB, Zhu C, Yong SK, et al (2009). Enhanced sensitivity of celecoxib in human glioblastoma cells: Induction of DNA damage leading to p53-dependent G1 cell cycle arrest and autophagy. Molecular Cancer, 8, 66.

Kang MK, Park W, Choi YL, et al (2009). The effect of cyclooxygenase- 2 expression on tumor volume response in patients treated with radiotherapy for uterine cervical cancer. J Korean Med Sci, 24, 1170-76.

Kim HS, Kim T, Kim M, et al (2013). Cyclooxygenase-1 and -2: Molecular Targets for Cervical Neoplasia. J Cancer Prevent, 18. 123- 34.

Kim SH, Hwang CI, Juhnn YS, et al (2007). Erratum: GADD153 mediates celecoxib-induced apoptosis in cervical cancer cells. Carcinogenesis, 28, 223-31.

Kim SH, Song SH, Kim SG, et al (2004). Celecoxib induces apoptosis in cervical cancer cells independent of cyclooxygenase using NF-kappaB as a possible target. $J$ Cancer Res Clin Oncol, 130, 551-60.

Kim YM, Pyo H (2013). Different Cell Cycle Modulation by Celecoxib at Different Concentrations. Cancer Biother Radiopharm, 28, 138-45.

Kimman M, Norman R, Jan S, et al (2012). The burden of cancer in member countries of the association of southeast asian nations (ASEAN). Asian Pac J Cancer Prev, 13, 411-20.

Lane DP, Cheok CF, Lain S (2010). p53-based cancer therapy. 
Cold Spring Harb Perspect Biol, 2, 1222 .

Larasati YA, Putri DPP, Utomo RY, et al (2014). Combination of cisplatin and cinnamon essential oil inhibits hela cells proliferation through cell cycle arrest. J App Pharm Sci, 4, 14-9.

Lee YS, Bae SM, Kwak SY, et al (2006). Cell cycle regulatory protein expression profiles by adenovirus p53 infection in human papilloma virus-associated cervical cancer cells. Cancer Res Treat, 38, 168-77.

Li T, Kon N, Jiang L, et al (2012).Tumor suppression in the absence of p53-mediated cell cycle arrest, apoptosis, and senescence. Cell, 149, 1269-83.

Liu K, Liu PC, Liu R, et al (2015). Dual AO/EB staining to detect apoptosis in osteosarcoma cells compared with flow cytometry. Med Sci Monit Basic Res, 21, 15-20.

Nair P, Somasundaram K, Krishna S (2003). Activated notch1 inhibits p53-induced apoptosis and sustains transformation by human papillomavirus type 16 E6 and E7 oncogenes through a activated notch1 inhibits p53-induced apoptosis and sustains transformation by human papillomavirus type 16 E6 and E7. J Virol, 77, 7106-112.

Pflaum J, Schlosser S, Müller M (2014). p53 family and cellular stress responses in cancer. Frontier Oncol, 285, 1-15.

Pinheiro NA, Villa LL (2001). Low frequency of p53 mutations in cervical carcinomas among Brazilian women. Brazilian J Med Biol Res, 34, 727-33.

Torre LA, Bray F, Siegel RL, et al (2015). Global Cancer Statistics, 2012. CA Cancer J Clin, 15, 87-108

Vici P, Mariani L, Pizzuti L, et al (2014). Emerging biological treatments for uterine cervical carcinoma. J Cancer , 5, 86-97.

Sahasrabuddhe VV, Parham GP, Mwanahamuntu MH, et al (2013). Cervical cancer prevention in low- and middleincome countries: Feasible, Affordable, Essential. Cancer Prev Res (Phila), 5, 11-17.

Setiawati A, Immanuel H, Utami MT (2016). Typhonium flagelliforme lodd. blume leaf extract inhibits COX-2 expression on WiDr colon cancer cells. Asian Pac J Trop Biomed, 6.

Wang L, Liu LH, Shan BE, et al (2009). Celecoxib promotes apoptosis of breast cancer cell line MDA-MB-231 through down-regulation of the NF-kappa B pathway. Chin J Cancer, 28, 6 .

Wang Y, Niu X, Yang L, et al (2013). Effects of Celecoxib on Cycle Kinetics of Gastric Cancer Cells and Protein Expression of Cytochrome C and Caspase-9. Asian Pac J Cancer Prev, 14, 2343-47.

Yuliani SH, Anggraeni CD, Sekarjati W, et al (2015). Cytotoxic Activity of Anredera cordifolia Leaf Extract on HeLa Cervical Cancer Cells through p53-Independent Pathway. Asian J Pharm Clin Res, 8, 328- 31.

Zweers MC, de Boer TN, van Roon J, et al (2011). Celecoxib: considerations regarding its potential disease-modifying properties in osteoarthritis. Arthritis Res Ther, 13, 239. 